\title{
Experiencias didácticas, un medio de acercamiento a la lectura
}

\author{
Leidy Carmenza Acuña Pérez * \\ Silvia Alejandra Ruiz Núñez ** \\ Mauricio Uricoechea Guzmán ****
}

Artículo de reflexión

Fecha de Recepción: 23 julio 2018.

Fecha de Aprobación: 4 noviembre 2018.

\section{Resumen}

Este artículo da cuenta de los avances de una investigación en curso, cuyo objetivo es proponer experiencias didácticas que animen al niño a leer; las experiencias didácticas se dividen en prácticas de aula, prácticas virtuales y salidas pedagógicas que son aplicadas a 25 estudiantes del curso $6-2$ de la Institución Educativa Libertador Simón Bolívar del municipio de Tunja. La investigación surge de la necesidad de hacer de la lectura una actividad interesante ya que un gran número de estudiantes de grado $6^{\circ}$ muestran apatía al realizar cualquier actividad lectora. El enfoque metodológico de la investigación es cualitativo y sigue las etapas descritas por Kemmis \&
McTaggart sobre investigación acción (planificación, acción, observación y reflexión). Las técnicas de recolección de datos utilizadas fueron la observación y la encuesta y, para el análisis de la información se hizo uso de fichas de valoración. Finalmente, se espera que los estudiantes de grado sexto, a través de nuevas experiencias lectoras, adquieran gusto por leer, amplíen su visión frente a diferentes alternativas de trabajo y reconozcan la importancia de la lectura en su formación personal y académica.

Palabras clave: lectura, animación a la lectura, experiencia didáctica, prácticas de aula, prácticas pedagógicas, prácticas virtuales, investigación acción.
* Institución Educativa Libertador Simón Bolívar Boyacá - Colombia leidyca84@gmail.com ** Institución Educativa Libertador Simón Bolívar Boyacá - Colombia silviaruiz20@yahoo.es *** Universidad Pedagógica y Tecnológica de Colombia, Boyacá Colombia. mauguz1967@yahoo.es

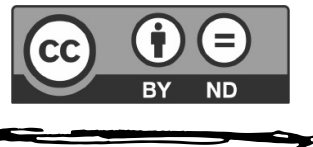




\section{Introducción}

La lectura es una actividad que nos llena de placer, hace nuestra vida diferente, crea en el ser humano la capacidad de transformar ideas, pensamientos y comportamientos; sin embargo, la lectura ha perdido su papel fundamental en el desarrollo de la sociedad y, en especial, entre la comunidad educativa. El Estado, a través de sus políticas educativas, ha propuesto diferentes alternativas para promover esta actividad, pero se observa mayor dificultad en las habilidades lectoras en niños y jóvenes, derivadas en gran parte, de didácticas inadecuadas, falta de motivación por leer y uso incorrecto de las tecnologías de la información y la comunicación.

Este trabajo de investigación se está llevando a cabo en la Institución Educativa Libertador Simón Bolívar del municipio de Tunja, que se encuentra ubicada al sur de la ciudad; cuenta con una zona poblacional de estratos $1 \mathrm{y}$ 2. Los estudiantes de la institución, en su mayoría, enfrentan situaciones familiares, emocionales, sociales y económicas dificiles que los conducen a mostrar apatía ante algunas prácticas lectoras o académicas, convirtiéndose así la institución en un refugio a sus problemas y no en un lugar de superación y conocimiento; por otro lado, desde el quehacer docente, se han utilizado diferentes estrategias para fortalecer la comprensión lectora sin tener en cuenta los intereses lectores del estudiante, lo que ha generado bajo desempeño académico y resultados no muy favorables en pruebas externas e internas de la Institución.
Cada vez es más evidente la apatía y despreocupación por parte de los estudiantes ante el desarrollo de cualquier actividad lectora, porque desde el hogar no se ha creado el hábito lector y en la escuela se ha dejado un poco de lado el desarrollo de actividades que promuevan la lectura. La lectura es una actividad práctica y de goce y si el docente, no despierta el interés y amor por ella, difícilmente los estudiantes alcanzaran las competencias lectoras que necesitan para desarrollar un adecuado proceso académico; por otro lado, los docentes debemos ser agentes dinamizadores de esa animación por la lectura, crear el hábito y el goce lector desde los primeros grados de escolaridad.

Teniendo en cuenta lo anterior, el proyecto busca proponer experiencias didácticas como salidas de campo, prácticas virtuales y de aula que contribuyan a animar la lectura en estudiantes de grado sexto de la IELSB. Cada experiencia didáctica ha sido seleccionada de acuerdo con los intereses y necesidades del estudiante en torno al proceso lector. Cabe resaltar que, si no se logra la motivación por la lectura muy difícilmente se pueden llevar a cabo procesos de comprensión lectora.

Para la consolidación de este trabajo se hizo una revisión y aproximación de proyectos afines; entre los cuales están:

Estimular el placer de leer: propuesta de animación lectora para alumnos de sexto de primaria "Esta investigación tuvo como finalidad aportar una nueva manera de abordar la lectura en grado sexto de primaria para favorecer, en los 
alumnos, el gusto por la lectura a partir de actividades motivadoras" (Fernández, 2014, p.5).

Leer para construir, proyecto de animación y promoción de lectura en los estudiantes de quinto grado del Gimnasio Campestre Beth Shalom:

El objetivo principal de la investigación fue sensibilizar a los estudiantes y profesores del colegio sobre la importancia de la lectura en los procesos de aprendizaje a través de la propuesta didáctica "Programa de Promoción y Animación a la lectura”. Este proyecto reitera la importancia que tiene la escuela, junto con sus docentes, de impartir a los niños un espíritu lector $\mathrm{y}$, en reconocer que en el quehacer pedagógico se puede lograr mucho más que la repetición de información para reproducirla en un examen escrito; pues la verdadera educación se da cuando se motiva y se forma un lector y escritor competente. (Morales, 2010, p.20)

Estrategias didácticas para formar lectores autónomos:

Este proyecto consistió en vincular a los alumnos de grado $6^{\circ}$ del Instituto técnico integrado de promoción social, del municipio de Monguí (Boyacá), de la lectura por gusto y placer a la lectura autónoma, de tal manera que vean en ella la posibilidad de cambiar su entorno, de mejorar su rendimiento, de estar en la capacidad de proponer, discernir e interactuar; y por supuesto, conseguir que no se lea bajo ningún tipo de presión. (Barrera, 2007, p.5)

\section{Teorías del conocimiento}

Los referentes teóricos que orientan el trabajo de investigación son: el concepto de lectura, desde lo pedagógico con autores como Celestín Freinet y Lev Vygotsky ya que ellos abordan la lectura como un proceso socio-cultural y de libertad; y, desde la psicología e investigación educativa con autores como Ana Solé, Daniel Cassany, Beatriz Helena Robledo y José Quintanal Díaz, ya que sus investigaciones y escritos sugieren diferentes estrategias de acercamiento entre el texto y el lector; además, Beatriz Helena Robledo y José Quintanal Díaz hacen énfasis en la importancia del docente como mediador en la enseñanza de la lectura. Al mismo tiempo, se hace referencia a teorías del conocimiento sobre animación a la lectura y al uso correcto de los recursos didácticos.

\section{Enseñanza de la lectura}

Por décadas se ha trabajado e investigado sobre qué es la lectura y los métodos de enseñanza sobre ésta. Al inicio, la lectura fue vista como un proceso de decodificación de símbolos e incluso Cassany (2006) afirma que: "Todavía hoy muchas personas creen que leer consiste en oralizar la grafía, en devolver la voz a la letra callada” (p.1). Pero esta concepción se descartó hace tiempo por tratarse de un enfoque mecánico.

Más moderna y científica es la visión de que leer es comprender. Para comprender es necesario desarrollar varias destrezas mentales o procesos cognitivos: anticipar lo que dirá un escrito, aportar nues-
El objetivo principal de la investigación fue sensibilizar a los estudiantes y profesores del colegio sobre la importancia de la lectura en los procesos de aprendizaje a través de la propuesta didáctica "Programa de Promoción y Animación a la lectura". 
Leer es un proceso cognitivo complejo. que activa estrategias de alto nivel: dotarse de objetivos, establecer y verificar predicciones, controlar lo que se va leyendo, tomar decisiones en torno a dificultades o lagunas de comprensión, diferenciar

lo que es esencial de la información secundaria. tros conocimientos previos, hacer hipótesis y verificadas, elaborar inferencias para comprender lo que sólo se sugiere, construir un significado, etc. Llamamos alfabetización funcional a este conjunto de destrezas, a la capacidad de comprender el significado de un texto. $Y$ denominamos analfabeto funcional a quien no puede comprender la prosa, aunque pueda oralizarla en voz alta. (Cassany, 2006, p.1)

Esta idea de lectura deja claro que para leer se requieren desarrollar procesos cognitivos, más allá de la identificación y el reconocimiento de grafías ya que "todos podemos leer del mismo modo y todos podemos aprender a leer del mismo modo. Lo que se necesita es aprender a realizar estas destrezas cognitivas (Cassany, 2006).

Para complementar el concepto que Cassany propone sobre el acto de leer, se encuentra el de Solé (1995) quien nos dice:

Leer es un proceso cognitivo complejo. que activa estrategias de alto nivel: dotarse de objetivos, establecer y verificar predicciones, controlar lo que se va leyendo, tomar decisiones en torno a dificultades o lagunas de comprensión, diferenciar lo que es esencial de la información secundaria. Este proceso requiere necesariamente de la implicación activa y afectiva del lector. No es un aprendizaje mecánico, ni se realiza todo de una vez. (p.3)

La buena práctica lectora en el niño o niña es el resultado de lo que él o ella ven de las personas que los rodean, es decir si el niño ve que sus padres son lectores, es muy probable que exista una tendencia de él hacia la lectura, pero si las personas de su entorno inmediato no leen, es probable que el niño tampoco lo haga. Para Freinet "El proceso normal para el aprendizaje de la lecto-escritura es una constante de aproximación a los modelos adultos que el individuo trata instintivamente de imitar con la mayor perfección” (citado en Jiménez, 2008, p.2).

Sin lugar a dudas, "a leer se aprende leyendo, y que como en todos los ámbitos del aprendizaje, los aprendices utilizan todos los medios a su alcance para lograrlo" (Solé, 1995, p.3). Y es el docente quien debe mediar entre el alumno y la lectura, procurar trabajar en la Zona de Desarrollo Próximo de sus educandos, es decir, para cada alumno se necesitarán diferentes ayudas o andamiajes. Algunos necesitarán motivación para la lectura, otros necesitarán generar o recoger mayor conocimiento previo sobre el tema del que se va a leer, otros, sin embargo, tendrán problemas para inferir, y otros, para descubrir la macroestructura del texto porque se centran más en los detalles.

Vygotsky (como se citó en Jiménez, 2008) explicaba en su concepto de la "zona de desarrollo próximo" cómo no se avanza en este potencial partiendo de lo que el niño ya sabe, sino a partir de interacciones nuevas con personas adultas o más expertas. En ese sentido Vygotsky, por un lado, difería de la concepción constructivista del aprendizaje y, por otro lado, defendía la importancia de la inte- 
racción con todas las personas del entorno del niño, no únicamente con las personas docentes y en el aula. (p.2)

Lo anterior significa un cambio en la manera de abordar la lectura en el aula, que va desde identificar las necesidades e interés de los estudiantes hasta buscar y adaptar estrategias que conlleven a trabajar la lectura no como un ejercicio mecánico sino como un proceso de desarrollo del pensamiento.

Vigostky (como se citó en Becco, 1999) piensa que el conocimiento no es un objeto que se pasa de uno a otro, sino que es algo que se construye por medio de operaciones y habilidades cognoscitivas que se inducen en la interacción social... el desarrollo intelectual del individuo no puede entenderse como independiente del medio social en el que está inmersa la persona. Teniendo en cuenta lo anterior, no se puede dejar de lado el contexto donde el lector se desenvuelve ya que este determina su interés y actitud a la hora de realizar cualquier actividad. (p.2)

\section{El placer de leer}

La lectura se ha convertido en un proceso interactivo en el cual el lector deja de ser pasivo para buscar una relación activa con el texto. La psicología e investigación educativa han aportado valiosos elementos para transformar la enseñanza de la lectura en la escuela; sin embargo, la realidad social a la que se enfrentan a diario los estudiantes ha aumentado el desinterés por realizar cualquier actividad lectora y a esto se suma que muchos de los niños y niñas no tienen oportunidades, fuera de la escuela, para familiarizarse con la lectura. Solé (1996) afirma:

...los niños para aprender a leer, necesitan percibir la lectura como un reto interesante, algo que los desafía, pero que podrán alcanzar con la ayuda que les proporciona su maestro; deben darse cuenta de que aprender a leer es interesante y divertido, que les permite ser más autónomos. Han de percibirse a sí mismos como personas competentes, que con las ayudas y recursos necesarios, podrán tener éxito y apropiarse de ese instrumento que les será tan útil para la escuela y para la vida. (p.4)

Como vemos, la lectura cobra importancia cuando el medio hace de ella una actividad cotidiana, libre y espontánea, convirtiéndola en "una práctica cultural insertada en una comunidad particular, que posee una historia, una tradición, unos hábitos y unas prácticas comunicativas especiales (Cassany, 2006, p.42). Por lo anterior, se hace necesario ver a la lectura como una práctica social y cultural para que los niños la utilicen como medio de comunicación placentero y de aprendizaje; de ahí, la importancia de relacionarla con el contexto y de sembrar en los estudiantes actitudes positivas frente a su proceso lector.

Según Cassany (2006):

Leer no es sólo un proceso psicobiológico realizado con unidades lingüísticas y capacidades mentales. También es una práctica cultural insertada en una comunidad particular, que posee una historia, 
una tradición, unos hábitos y unas prácticas comunicativas especiales. No basta con saber decodificar las palabras o con poder hacer las inferencias necesarias. Hay que conocer la estructura de cada género textual en cada disciplina, cómo lo utiliza el autor y los lectores, qué funciones desarrolla, cómo se presenta el autor en la prosa, qué conocimientos deben decirse y cuáles deben presuponerse, cómo se citan las referencias bibliográficas, etc. (p.8)

El goce y el placer por realizar cualquier práctica lectora, en su mayoría, es una cuestión individual, donde todos los elementos alrededor del lector juegan un papel primordial de ahí la importancia de reconocer e identificar gustos, concepciones, creencias, contexto... para inducir la lectura. "No se puede olvidar que leer es un proceso de interacción entre el escrito y el lector, guiado por los propósitos que mueven a éste" (Solé, 1995, p 3).

Los alumnos deben sentirse motivados para aprender a leer, deben darse cuenta de que esta actividad es divertida e interesante, en cuanto conocen, exploran, imaginan y crean; es el camino que los conduce a ser seres más autónomos y competentes. Cuando logran apropiarse y sumergirse en el mundo de la lectura podrán tener el éxito esperado. Para Solé (1995): "Ayudar a los alumnos a leer, interesarlos por la lectura, es dotarles de un instrumento de culturización y de toma de conciencia cuya funcionalidad escapa a los límites de la institución” (p. 4).

A modo de conclusión, la lectura es una actividad libre, espontánea, amena en la cual el docente es eje fundamental para llevar a cabo un proceso bonito y satisfactorio.

La enseñanza de la lectura no debe hacer que su aprendizaje constituya una carga abrumadora para el niño, que lo haga sentirse incompetente para apropiarse de un instrumento que le va a ser tan necesario. Es imposible que nadie pueda encontrar satisfacción en algo que le representa un esfuerzo insalvable, que le devuelve una imagen devaluada de sí mismo. (Solé, 1995, p. 4).

\section{Animación a la lectura}

Desde hace tiempo formar lectores ha sido una responsabilidad únicamente de la escuela, donde se ha reducido la enseñanza de la lectura a un proceso mecánico, sin tener en cuenta el contexto del estudiante. "La lectura se ha visto como un desciframiento de códigos y de ejercicios repetitivos y no como un proceso de construcción de sentido y de transformación de la realidad" (Robledo, 2010, p.35).

De acuerdo con lo anterior, el reto que tiene la escuela hoy es la incorporación de la lectura como una práctica social; por esto la animación hacia la lectura se considera como una práctica educativa significativa, que de acuerdo con Robledo (2010) consiste en:

...acercar a las personas a los materiales de lectura. Quien anima infunde soplo vital a los textos, pero también anima al lector a entablar una relación más personal con los materiales de lectura. La animación requiere de un mediador y hay un 
arte en este oficio muy relacionado con las artes interpretativas. El animador $\mathrm{da}$ pistas, ofrece claves para una mejor interpretación de los textos. El animador orienta la exploración de estos. Su intervención es fundamental para que los lectores encuentren caminos personales para la apropiación y uso de la lectura, y en ese camino, el mediador también se transforma. (p.35)

La animación hacia la lectura en la escuela, depende en gran medida de los recursos didácticos que el docente utilice para generar el ambiente propicio en el que los estudiantes se interesen por leer. Esta animación a la lectura nos lleva a generar una cultura lectora que puede manifestarse en diferentes aspectos: ambiente, diversificación de materiales, diálogos con textos y los contextos, intercambio de conocimiento y experiencias lectoras; tan es así, que "la animación a la lectura concierne a cualquier tarea que desde las bibliotecas, las aulas, los hogares, las librerías o cualquier otro ámbito favorezca la aproximación de los niños o los adultos, a los libros” (Mata, 2008, p.70).

Si bien la apropiación del texto es una de las finalidades de la lectura, que solo se consigue si se lleva a cabo por gusto y no por obligación, es de tener en cuenta que no es el único objetivo a alcanzar, para Jiménez (2012) algunos de los objetivos de la animación a la lectura son:

Desarrollar la imaginación y la creatividad.

Crear un clima positivo, ameno, lúdico y favorable hacia la lectura, fomentando el interés hacia la lectura y los libros.

Hacer que se tome conciencia de la importancia de los libros como fuente de entretenimiento y de información.

Ampliar sus horizontes culturales.

Desarrollar su capacidad creativa y recreativa a partir de la lectura.

Experimentar el juego como herramienta de aprendizaje.

Aumentar el universo léxico y adquirir mayor competencia lingüística y comunicativa. (p.67)

La animación lectora comprende cuatro características y cinco técnicas que Quintanal, en su libro "La animación lectora en el aula, técnicas, estrategias y recursos" ha definido como:

\section{Características:}

- Permitir al niño desarrollar una "experiencia" de relación personal con el texto.

- Otorgarle autonomía, haciendo que lo consiga de modo activo y por sí mismo.

- Moviendo su espíritu y su voluntad, disfrutándolo.

- Lanzándolo a la búsqueda de otras nuevas lecturas.

\section{Técnicas:}

- Función docente: el docente desempeña el papel de animador, mediador y a la vez modelo de sus alumnos.
El animador da pistas ofrece claves para una mejor interpretación de los textos. El animador orienta la exploración de estos. Su intervención es fundamental para que los lectores encuentren caminos personales para la apropiación y uso de la lectura, y en ese camino, el mediador también se transforma. 
- Selección de la técnica: se debe tener en cuentas los textos, el desarrollo lúdico de la actividad y estimular la espontaneidad.

- Recursos: textos, libros, grabaciones, representaciones..., entre otros.

- Lugar: debe ser cómodo, cálido para predisponer la voluntad de los niños.

- Momento: debe ser un proceso claro, preciso y continuo para que sea efectivo.

\section{El rol del docente}

Es importante resaltar el papel del docente en el proceso lector, por cuanto es modelo, hace acompañamiento continuo, puede satisfacer interés lectores, generar momentos de práctica y realizar un adecuado programa en el que la lectura sea protagonista. Quintanal 2005 afirma:

Todo docente ha de generar sus propias estrategias de lectura, las cuales vendrán determinadas por las características e intereses personales (por cuanto es modelo de sus alumnos), la disponibilidad del aula (recursos y medios del entorno), los propios destinatarios (sus posibilidades e intereses) y el momento educativo en que se desarrollan (cada nivel, cada etapa, curso y alumno, responde a una lectura específica). (p.22)

El docente se convierte en ese compañero de viaje en el proceso de enseñanza, es un orientador innato que establece vínculos de afectividad con el estudiante y de quien depende, en gran medida, la motivación del niño o niña por su aprendizaje. Él o ella llega a convertirse en un mediador entre enseñanza - alumno - aprendizaje.

Vigotsky (como se citó en Beco, 1999) afirma que:

Los mediadores son instrumentos que transforman la realidad en lugar de imitarla. Su función no es adaptarse pasivamente a las condiciones del medio, sino modificarlas activamente... la experiencia de aprendizaje mediado es la manera en la que los estímulos remitidos por el ambiente son transformados por un agente mediador. Este agente mediador guiado por sus intenciones, su cultura y su inversión emocional, selecciona y organiza el mundo de los estímulos. Los tres componentes de la interacción mediada son: el organismo receptor, el estímulo y el mediador. El efecto de la experiencia de aprendizaje mediador es la creación en los receptores de una disposición, de una propensión actitudinal para beneficiarse de la exposición directa a los estímulos. Estos se pueden traducir en mediar para enseñar a aprender. (p.2)

Se reconoce que no todos los estudiantes tienen la posibilidad de interactuar con la lectura, ya que su medio no les brinda las herramientas necesarias para esta actividad, así que el docente, según Quintanal (2000):

Desarrollará un papel de mediación como favorecedor del contacto del niño con el libro. Esta acción mediadora potencia la actividad del lector en tres formas diferentes: provocando su derroche imaginativo y estimulando la recreación personal, 
organizando experiencias de lectura, tanto a nivel personal (que serán íntimas y estarán sujetas al propio control del lector) o compartidas (en el que la función docente desarrollará un papel fundamental en la intercomunicación de la propia experiencia de lectura), llevando a efecto actividades lúdicas, con los textos literarios o a partir de ellos. (p.116)

Para finalizar, la animación a la lectura depende de muchos factores sociales, en los que se desenvuelve el niño, pero el docente como agente dinamizador de procesos puede contribuir a un ambiente favorable y enriquecedor de lectura

\section{Experiencias didácticas}

El reto que tiene la escuela hoy en día se centra en la incorporación de prácticas sociales y culturales de lectura y escritura; Sin embargo, no es suficiente lo que las políticas educativas nos ofrecen, se hace necesario pensar y transformar aquellas experiencias didácticas, en especial, las que están relacionadas con la lectura ya que de estas depende, en gran medida, la disposición y actitud del estudiante.

Entendemos por experiencia didáctica el acercamiento y uso de "materiales didácticos $\mathrm{o}$ educativos que sirven como mediadores para el desarrollo y enriquecimiento del alumno. Favoreciendo el proceso de enseñanza y aprendizaje y facilitando la interpretación de contenido que el docente ha de enseñar” (González, 2015, p.15).

Desde esta perspectiva, las experiencias didácticas se han convertido en fuente generadora de conocimiento y motivación. El docente es quien orienta el proceso de formación y así mismo es el encargado de buscar, seleccionar y utilizar herramientas de apoyo que favorezcan el aprendizaje teniendo en cuenta los intereses de los estudiantes. Al respecto Quintanal (2005) afirma:
Para leer es necesario contar con medios para ello. Y "por medios" tenemos que entender lo mismo recursos (libros, materiales impresos, bibliotecas, etc.) que contextos y momentos apropiados para su aplicación, pues habrá que contemplar la aplicación personalizada del ejercicio lector (nos referimos a aquellas aplicaciones en las que el niño lee de forma intima) como la experimentación grupal, mediante acciones programadas de dinamización y desarrollo compartido. (p.22)

De cómo se presenten los recursos y las actividades a los estudiantes dependerá, en gran medida, el éxito o fracaso del proceso lector. La lectura cumple un papel fundamental en la construcción de conocimiento y de crecimiento personal, por eso es importante permitir y brindar espacios, momentos y recursos que despierten el interés por la lectura en niños y jóvenes.

Para que un material didáctico resulte eficaz en el logro de unos aprendizajes, no basta con que se trate de un "buen material", ni tampoco es necesario que sea un material de última tecnología. Cuando seleccionamos recursos educativos para utilizar en nuestra labor docente, además de su calidad objetiva hemos de considerar en qué medida sus 
características específicas (contenidos, actividades, tutorización...) están en consonancia con determinados aspectos curriculares de nuestro contexto educativo. (Marqués, 1996, p.5)

\section{Prácticas de aula.}

Nos encontramos en una sociedad cada vez más dependiente de las nuevas tecnologías, lo que ha desplazado un poco, las prácticas de aula y han alejado a los estudiantes de actividades de lectura y escritura; es por eso, que en el aula, la motivación es un punto que puede ser determinante en la comprensión de las temáticas por parte de los estudiantes, y mucha de la responsabilidad de hacer una clase llamativa para los alumnos recae sobre los docentes, en manos de quienes está crear un ambiente agradable y de seguridad que les permita a los niños y jóvenes demostrar sus habilidades. Tapia (1997) afirma que:

el clima motivacional que los profesores crean en el aula se traduce en la representación que los alumnos se hacen respecto a qué es lo que cuenta en las clases, que es lo que quieren de ellos el profesor y consecuencias puede tener, en este contexto, actuar de un modo u otro. (p. 5)

Promover el respeto por la particularidad de cada estudiante dentro del aula es fundamental, identificar las habilidades de cada uno y poner en práctica estrategias orientadas a que los estudiantes le hallen significado a las actividades que se están desarrollando y de esta manera orientarlos al logro.

Es importante que profesores y profesoras reflexionen sobre las características motivacionales de los alumnos desde una perspectiva dinámica. Es decir, se ha de considerar las implicaciones de la interacción entre las actuaciones del profesor, las respuestas de los alumnos, los efectos de las formas en que acometen sus tareas y los modos de apoyo e intervención del profesor a lo largo y después de éstas. (Tapia, 1997, p. 5)

En el aula, la interacción que el docente hace entre texto y lector se puede dar en actividades como: lectura de viva voz, trabajo de textos literarios, lectura paso a paso, juegos lectores, actividades de tradición oral, revisión de material informativo y expositivo, historias de vida, entre otras que permiten despertar la imaginación, sentir curiosidad e interés por conocer el contenido de un texto o por aprender a leer iconografías.

\section{Las salidas pedagógicas.}

Las salidas pedagógicas son un recurso eficaz para reforzar el aprendizaje del estudiante; sin embargo, en nuestro contexto educativo se le ha dado poca importancia a esta práctica educativa, debido a factores como la falta de recursos y de gestión por parte del personal administrativo; la concepción de algunos padres de familia quienes piensan que el aprendizaje solo está dentro del aula de clase. Se entiende por:

Salida pedagógica, aquellas actividades realizadas fuera del aula que ponen a los alumnos en contacto directo con la realidad para aprender de ella de manera que el estudiante recibe información de una forma activa, amena, motivadora, atractiva, 
participativa y significativa para él. Una salida bien planificada siempre es un recurso educativo válido y eficaz, que prepara al alumno para desarrollar estrategias de aprendizaje permanente, tomando como punto de partida su entorno, pero que puede hacerse extensiva a cualquier otra realidad. (Niño, 2012, p.5)

Esta clase de experiencia didáctica facilita que los estudiantes reconozcan y vivencien su medio y desarrollen competencias de manera práctica.

Además, la salida pedagógica se entiende como un instrumento de ayuda al alumno para conocer su entorno, sin que ello suponga ninguna pérdida de calidad en el aprendizaje, teniendo en todo el proceso del aprendizaje el contacto de la realidad que se quiere aprender y dejando que el estudiante soporte un proceso lógico de aprendizaje en el que el docente solo intervendrá sólo para solventar dudas durante el proceso de captación de la realidad aprendida (Mohamed et al., 2017, p.197).

Sin importar el lugar, el área, la edad de los estudiantes, siempre se les debe, en lo posible, brindar oportunidades reales de aprendizaje, que los involucren y pongan en contacto con su realidad. El generar ambientes de aprendizaje externos al aula, de entorno vivo, animan al estudiante a desarrollar y a fortalecer su proceso académico. La salida pedagógica siempre es y será una experiencia significativa ya que el alumno difícilmente olvida lo que lleva a la práctica.
"Las salidas pedagógicas o actividades fuera del aula, son un recurso pedagógico que ayuda en el aprendizaje de los estudiantes en todos los ámbitos en que se aplique” (Mohamed, Pérez \& Montero, 2017, p.195).

\section{La biblioteca y la animación a la lectura.}

En una sociedad dominada por las nuevas tecnologías de la información y la comunicación (TIC), y en la que nuestros niños y jóvenes viven inmersos en actividades que les proporcionan poco crecimiento personal y académico, su regreso a la biblioteca se convierte en una experiencia nueva y fundamental para propiciar el reencuentro entre el libro y el estudiante, con el fin de mostrarles un nuevo medio de aprendizaje, libre de imposiciones. "La biblioteca es una institución obligada a hacer animación y promoción de la lectura. En su rutina de trabajo debe incluir la organización de actividades" (Calvo, 1999, p.5).

Así la biblioteca se convierte en un espacio que al igual, que las Instituciones Educativas, deben contribuir con la formación y afianzamiento de hábitos lectores en sus alumnos, siendo la biblioteca una extensión del colegio en el proceso de enseñanza y aprendizaje.

Para Calvo (1999):

Los centros de enseñanza son compañeros necesarios de la biblioteca en las tareas de animación a la lectura. Cualquier actividad que se organice en ella ha de ser difundida en los colegios e institutos.
"Las salidas pedagógicas o actividades fuera del aula, son un recurso pedagógico que ayuda en el aprendizaje de los estudiantes en todos los ámbitos en que se aplique" 
La biblioteca escolar se entiende como un centro de recursos para la lectura en todas sus facetas, que va más allá de un conjunto de libros, y alrededor del cual se arma y diseña un plan formativo que da sentido a los materiales que lo componen.
Debemos buscar la complementariedad de actuaciones entre bibliotecas y centros de enseñanza. (p.6)

El espacio más cercano entre texto y lector es la biblioteca escolar porque es allí donde se obtiene información, se contrasta, verifica y se abre posibilidades de conocer nuevos mundos. Para Baró et al (2002):

La biblioteca escolar se entiende como un centro de recursos para la lectura en todas sus facetas, que va más allá de un conjunto de libros, y alrededor del cual se arma y diseña un plan formativo que da sentido a los materiales que lo componen. En este punto es importante insistir en lo imprescindible que resulta que la lectura sea considerada como objetivo clave y compartido por todas las áreas y materias curriculares; solo así la biblioteca escolar podrá desempeñar eficazmente su papel de herramienta y servicio que proporciona a todos los escolares espacios, tiempos y la posibilidad real de múltiples experiencias de lectura. (p.13)

Toda institución educativa debe contar con un espacio que genere conocimiento en el estudiante $y$, que a su vez, brinde de manera accequible, instrumentos y medios para fortalecer el aprendizaje. "La escuela, con la biblioteca como aliada, es la encargada de aportar conocimientos, desarrollar habilidades y cultivar actitudes positivas en los alumnos respecto a la lectura, la escritura y el manejo de la información" (Baró et al, 2002, p.15).

$\mathrm{Y}$, aunque se reconoce la importancia de la biblioteca, es indispensable acotar que este espacio está siendo reemplazado por las nuevas tecnologías y abandonado por las políticas educativas quienes han olvidado que "La biblioteca proporciona informaciones y recursos y educa para un uso consciente y eficaz de los mismos; ayuda así a formar lectores competentes, capaces de transformar la información en conocimiento" (Baró et al, 2002, p.18). De ahí, que los docentes retomemos esos espacios de aprendizaje y de contacto con el texto para resignificar el acto de leer y el aprendizaje.

\section{Nuevas tecnologías.}

Hoy en día, el uso de herramientas tecnológicas permiten procesar información con mayor rapidez porque resultan ser más atractivas para los niños, lo que despierta una motivación $\mathrm{y}$ un mayor interés en el aprendizaje por cómo se presenta el contenido de un texto (imágenes, videos, sonidos y realidad virtual) $y$, se han convertido en una fuente significativa del proceso de enseñanza-aprendizaje de la lectura.

Mayer (como se citó en Jiménez, 2008) ha señalado algunos principios que deben guiar la presentación de la información en formato multimedia a la hora de facilitar el aprendizaje, que se pueden aplicar también para el caso de la enseñanza de la lectura: 1) principio multimedia: se aprende mejor cuando las palabras se presentan con sus correspondientes dibujos más que cuando son presentadas aisladamente, es decir, con independencia de si estamos siguiendo una estrategia basada en la descodificación o una estrategia 
basada en la pronunciación global de la palabra; 2) principio de contigüidad espacial: se aprende mejor cuando la distancia entre las palabras y los dibujos es más próxima, ya que ambas representaciones pueden ser sostenidas en la memoria de trabajo simultáneamentey se puede disponer de otros recursos cognitivos; 3) principio de coherencia: se aprende mejor cuando se excluyen palabras y dibujos extraños; 4) principio de modalidad: se aprende mejor cuando las palabras son presentadas en forma de narración más que de forma visual, lo que permite que ambos canales sean usados, uno para el texto y otro para el dibujo, en lugar de usar sólo el canal visual ya que sería una sobrecarga para el sistema cognitivo de procesamiento; 5) principio de contigüidad temporal: se aprende mejor cuando las palabras y los dibujos son presentados simultáneamente más que de forma sucesiva. (p.5)

Por otro lado, estamos en los tiempos en que las tecnologías de la información y comunicación, están alcanzando todos los sectores sociales, económicos, culturales, políticos y educativos, teniendo una fuerte influencia en lo que se denomina sociedad del conocimiento, en donde las personas cada día deciden de qué manera acceden a la información y que parte de esta usan para resolver situaciones de su cotidianidad (Muñoz, 2016). "Desde el ámbito educativo que es donde me muevo, podemos decir que con el uso de las TIC, los métodos y estrategias didácticas han variado, al igual que la dinámica de los contenidos que se desarrollan en el aula" (Cabero, 2007, p. 8).
Las TIC han sido un factor determinante del cambio en algunos escenarios, estos cambios cruciales, en donde más que aceptación es adaptación de las TIC en nuestra cotidianidad, más concretamente en nuestra práctica docente; hemos incorporado no solo las TIC, sino también una serie de términos en nuestro vocabulario tales como brecha digital, blog, redes de aprendizaje, redes sociales, nativos digitales, migrantes digitales, entre otros, todos estos cargados de significados. Ahora bien hay que tener en cuenta que la presencia de las TIC en las instituciones educativas, desafían a las mismas a que sean responsables no solo de la adquisición sino de la transmisión y formación del colectivo docente. "Las nuevas tecnologías son poderosas herramientas didácticas que nos permiten a los docentes que las utilizamos, ofrecer a nuestros dicentes potentes aplicaciones complementarias a las disertaciones al uso" (Alcalá \& Rasero, 2010, p.398).

En este sentido, el desafío no solo lo asume la institución sino que también los profesores quienes deseamos generar cambios y transformaciones en nuestra práctica pedagógica. Para concluir se retoma la concepción de Alcalá \& Rasero (2010):

El acto de leer desarrolla capacidades y mejora los ámbitos de aprendizaje potenciando modelos de acción y de conducta personal, estamos muy de acuerdo con los sistemas educativos que apuestan por el hábito lector en consonancia con las tecnologías de la información y la comunicación. (p.404) 


\section{Metodología}

Esta investigación se está llevando a cabo con 25 estudiantes pertenecientes al curso sexto dos de la IELSB. Su enfoque metodológico es cualitativo, entendido este como "un conjunto de prácticas interpretativas que hacen al mundo visible, lo transforman y convierten en una serie de representaciones en forma de observaciones, anotaciones, grabaciones y documentos" (Hernández, Fernández \& Baptista, 2014, p.9). Se opta por el tipo de investigación acción, que para Kemmis \& McTaggart (1992) es "una forma de indagación introspectiva colectiva emprendida por participantes en situaciones sociales, con objeto de mejorar la racionalidad y la justicia de sus prácticas sociales o educativas, así como la comprensión de esas prácticas y de las situaciones en que estas tienen lugar” (p.9). Así mismo, Elliot (2005) define la investigación-acción, "como el estudio de una situación social para tratar de mejorar la calidad de la acción en la misma" (p.88).

Para el desarrollo de este trabajo, se tienen en cuenta las etapas de la investigación acción planteadas por Kemmis \& McTaggart (2005): planificar, actuar, observar y reflexionar.

\section{Etapa de Planificación}

"Es un plan que debe ser flexible para adaptarse a efectos imprevistos y a limitaciones anteriormente indiscernibles" (Kemmis \& McTaggart, 1992, p.17).

Esta etapa tuvo su origen a partir de observaciones realizadas durante la práctica docente, y se evidenció que los estudiantes muy pocas veces realizan las actividades de lectura de forma completa. Por esta razón, se pensó en una investigación con la que se lograra despertar el interés de los alumnos por leer.

A continuación, se describen cada uno de los momentos que se han tenido en cuenta para la consolidación de este trabajo de investigación:

- Revisión y análisis de documentos institucionales (proyecto Institucional, índice sintético de calidad y proyectos de lectura)

- Consulta y delimitación de los referentes teóricos y metodológicos que fundamentan la investigación.

- Diseño, aplicación y análisis de una encuesta con el fin de identificar los intereses lectores de los estudiantes.

\section{Etapa de acción}

"Debe ser fluida y dinámica y exige decisiones instantáneas acerca de que debe hacerse, así como el ejercicio de un raciocinio práctico" (Kemmis \& McTaggart, 1992, p.19).

Según Quintanal (2000), "existen diversas técnicas que contribuyen a fomentar la lectura, las que están agrupadas para facilitar su uso dependiendo de sus fines" (p.117). Por tanto, las doce experiencias a utilizar se seleccionaron teniendo en cuenta los resultados obtenidos en la encuesta y las técnicas o estrategias dadas por Quintanal.

En esta etapa se utilizaron instrumentos para la recolección de la información 
como diarios de campo, "que son informes personales en los que se plasman las reacciones y opiniones de los docentes frente temas de interés o a las preocupaciones de los estudiantes" (Kemmis y McTaggart, 1992, p.133); el cuestionario, "un instrumento basado en preguntas abiertas o cerradas para obtener información de los estudiantes" (Kemmis \& McTaggart, 1992, p.134); guía de observación, que contiene los elementos que son pertinentes para el proceso de sistematización (de acuerdo a la decisión de que sistematizar) (Mejía, 2012, p.60).

Selección y puesta en práctica de las experiencias didácticas teniendo en cuenta los resultados de la encuesta.

Las experiencias didácticas están distribuidas en:

Cuatro salidas pedagógicas: que buscan mostrar a los estudiantes ambientes de lectura diferentes al cotidiano.

- Biblioteca municipal: encuentro de los alumnos con los libros mediante un taller de lectura orientado por personal especializado.

- Museo de historia natural de la Universidad Pedagógica y Tecnológica de Colombia: reconocimiento de información y de espacio a través de lecturas cortas.

- Canal TElesantiago: dar a conocer un lugar de encuentro en donde los estudiantes reconocen la importancia de la lectura desde diferentes ámbitos.
- Biblioteca Universidad Pedagógica y Tecnológica de Colombia: realizar un recorrido en la biblioteca, para conocer sus principales funciones

- Visita a sedes de primaria de la IELSB: los estudiantes tienen la oportunidad de realizar la representación de su lectura preferida ante estudiantes de básica primaria.

Cuatro actividades virtuales:

- Del cuento a la película: completar una ficha de información sobre cuentos que se han llevado al cine (Valdivia, 2009, p.15). Esta actividad fue modificada para ser desarrollada de forma virtual.

- Escrilandia: recurso educativo virtual, donde los estudiantes tienen la oportunidad de ilustrar y cambiar el final de varias historias.

- Cree sus propias historietas: con base en su lectura preferida, los estudiantes representan el texto en forma virtual.

- Tras de cámaras: actividad de observación sobre la elaboración de diferentes materiales de lectura.

Cuatro actividades de aula:

- Conociendo experiencias: los estudiantes conocen las experiencias de vida de un escritor invitado.

- Juego gigante de memoria: los estudiantes relacionan imágenes con el texto dado (Valdivia, 2009, p.7).

- Tras la pista de...: los estudiantes resuelven un caso leyendo y "un instrumento basado en preguntas abiertas o cerradas para obtener información de los estudiantes" 
encontrando las pistas (Valdivia, 2009, p.6)

- Batallas de lecturas: encuentro con diferentes clases de texto (los cuales están en desorden), los estudiantes organizar los párrafos para armar un mural (Valdivia, 2009, p.5)

\section{Etapa de observación}

Tiene la función de documentar los efectos de la acción críticamente informada, proporciona la base inmediata para la reflexión. La observación es necesaria para que la acción no se vea recortada por las limitaciones de la realidad (Kemmis \& McTaggart, 1992, p.18).

En la investigación se lleva un diario de campo y fichas de observación, registros fotográficos y grabaciones en video. Las fichas de observación están diseñadas con parámetros específicos, para delimitar la información y son una base para la descripción de cada uno de los momentos durante la aplicación de los recursos didácticos; los registros fotográficos sirven como evidencia de los momentos y materiales usados durante cada sesión; las grabaciones en video aportan información que no se alcanza a registrar en los diarios de campo, pero que es fundamental en el análisis y reflexión acerca de la pertinencia de las experiencias lectoras.

\section{Etapa de reflexión}

Rememora la acción tal como ha quedado registrada a través de la observación, pero es un elemento activo. La reflexión pretende hallar el sentido de los procesos, los problemas y las restricciones que se han manifestado en la acción estratégica (Kemmis \& McTaggart, 1992, p.19).

La información obtenida de los diarios de campo, fichas de observación lectora y fichas de valoración diligenciadas por los estudiantes, permiten analizar y reflexionar sobre la pertinencia del trabajo investigativo y al mismo tiempo repensar en nuevas estrategias y espacios que ayuden a fortalecer el proceso lector y de aprendizaje en los estudiantes. Como docentes esta reflexión contribuye a fortalecer nuestras prácticas pedagógicas, con el uso de recursos y material adecuado para los estudiantes y, al mismo tiempo, nos permite ser conscientes de la importancia de ser ejemplo como agentes dinamizadores en el proceso lector.

\section{Resultados esperados}

- Los estudiantes de grado sexto de la IELSB, tienen la oportunidad de experimentar con otros ambientes de aprendizaje, amplían su visión frente a nuevas alternativas de trabajo con la lectura y reconocen la importancia que ésta tiene para su formación personal y académica.

- Desdela Institución Educativa, se puede organizar y llevar a cabo propuestas que involucren dinámicamente a los estudiantes con la lectura.

- La socialización de estas experiencias permite que los docentes realicen un trabajo colaborativo y más comprometido con la formación integral del estudiante. 
- El uso de recursos tecnológicos demanda una constante actualización de conocimientos y estrategias por parte de los docentes, para lograr un acercamiento más ameno con el estudiante.

\section{Conclusiones}

La lectura es fuente vital de conocimiento, poder en la construcción de una sociedad, hace al ser humano libre y dueño de sus pensamientos, acciones y palabras. La lectura enriquece el alma y acompaña sentimientos, de ahí la importancia de darle el valor fundamental entre nuestra comunidad educativa teniendo al docente como pionero de nuevas experiencias lectoras.

Confirmando las concepciones de animación a la lectura, expuestas por Quintanal Díaz y Robledo, se establece una relación entre el lector y el texto de manera lúdica, placentera, amena y creativa, lo que conlleva a desarrollar habilidades lectoras en forma significativa. Todo niño o niña que ha sido expuesto a actividades de animación lectora crea en él o en ella un gusto y placer por leer. Así mismo, la animación a la lectura es una serie de actividades, recursos y estrategias que en conjunto buscan que la lectura sea un proceso más llamativo y accesible para los estudiantes, ya que por medio de su participación en experiencias que no se llevan a cabo comúnmente en la Institución se logra despertar su deseo por leer, favoreciendo de esta manera su acercamiento a los libros.

La lectura tiene un sentido cultural y social por lo que es necesario que padres de familia y docentes seamos modelos activos de prácticas lectoras, que fomenten hábitos lectores adecuados en los estudiantes desde sus primeros años de escolaridad.

Los estudiantes establecen una relación más amable con su proceso lector, desarrollándolo por iniciativa propia y no por obligación. Ven la lectura no solo, como una forma para lograr buenos resultados académicos, sino como un medio de culturización y socialización.

Con la puesta en práctica de esta investigación se logra la intervención directa en las prácticas de aula mediante el aprovechamiento de espacios y recursos que hasta el momento han sido poco utilizados; así mismo, con el desarrollo de actividades en diferentes escenarios se consigue despertar mayor interés por la lectura en los estudiantes.

En el aula se requiere de una constante dinamización de las actividades a desarrollar con los estudiantes, práctica que se facilita a través de la investigación acción, con la que el docente puede planificar, observar, llevar a la acción y reflexionar sobre una situación que necesite ser intervenida y transformada.; además, La investigación acción permite transformar positivamente un contexto educativo permitiendo que padres de familia, docentes y estudiantes realicen un trabajo colaborativo.

En nuestro quehacer como docentes, ser generadores y guías de experiencias enriquecedoras en nuestra Institución Educativa, nos permite crecer personal y profesionalmente; compartir con nuestros estudiantes nuevos ambientes de aprendizaje fortalece la relación con ellos. 


\section{Referencias}

Alcalá, J., \& Rasero, J. (2010). El papel de las TIC en la animación a la lectura: Revista Latinoamericana de tecnología educativa. (3), 395 - 416.

Baró, M., Cencerrado, L., Cerrillo, P., Corchete, T., Coronas, M., Pacho, R., Tejero, A., \& Yuste, E. (2002). La biblioteca escolar como espacio de aprendizaje. Madrid, España: Editorial GRAFO, S. A

Barrera, S. J. (2007). Estrategias didácticas para formar lectores autónomos (tesis de pregrado). Universidad Pedagógica y Tecnológica de Colombia, Tunja, Colombia.

Cassany, D. (2006). Tras las líneas. Barcelona, España: Editorial Anagrama.

Cabero, J. (2007). Las necesidades de las TIC en el ámbito educativo: oportunidades, riesgos y necesidades. Tecnología y comunicación educativas. (45), 6-16.

Calvo, B. (1999). Animación a la lectura. Educación y biblioteca. (100), 5 - 7.

Delgado, B (2007). Fundamentos del proceso lector. Motivar la lectura en educación secundaria. OCNOS. (3), 39-53.

Domínguez, M. (2010). Estrategias para fomentar la lectura. Padres y maestros. (333), 5-9.

Elliott, J. (2005). El cambio educativo desde la investigación - acción. Madrid, España: Ediciones Morata.

González, I. (2015). El recurso didáctico. Usos y recursos para el aprendizaje dentro del aula. Escritos en la facultad. (109), 15 - 17.

Guerrero, A. (2009). Los materiales didácticos en el aula. Temas para la educación. (5), 1-7.

Hernández, R., Fernández, C., \& Baptista, M. (2014). Metodología de la investigación. México D. F., México: Mc Graw Hill.

Jiménez, J. (2008): Enseñanza de la lectura: de la teoría y la investigación a la práctica educativa. Revista iberoamericana de educación. (45), 2 - 22.

Jiménez, L. (2012). La animación a la lectura en las bibliotecas... La construcción de un camino hacia la lectura. Boletín de la asociación andaluza de bibliotecarios. (103), 59-78.

Kemmis, S., \& McTaggart, R. (1992). Cómo planificar la investigación acción. Barcelona, España: Romanya/Valls, S. A. 
Mata, J. (2008). Animación a la lectura: hacer de la lectura una práctica feliz, trascendente y deseable. Barcelona, España: Editorial GRAO.

Mejía, M. (2012). Sistematización: una forma de investigar las prácticas y de producción de saberes y conocimientos. La Paz, Bolivia: Ministerio de Educación.

Mohamed, M., Pérez, M., \& Montero, M. (2017). Salidas pedagógicas como metodología de refuerzo en la Enseñanza Secundaria. Reidocrea. 6(16), 194-210.

Morales, L. F. (2010). “Leer para construir": Proyecto de animación y promoción de lectura en los estudiantes de quinto grado del gimnasio campestre Beth Shalom (tesis de pregrado). Universidad de la Salle, Bogotá, Colombia.

Muñoz, H. A. (2016). Mediaciones tecnológicas: nuevos escenarios de la práctica pedagógica. Praxis \& Saber, 7(13), 199-221. https://doi. org/10.19053/22160159.4172

Naranjo, M. N. L. (2009). Motivación: perspectivas teóricas y algunas consideraciones de su importancia en el ámbito educativo. Revista educación. (33), 153-170.

Niño, M. (2012). Las salidas escolares en la educación primaria (tesis de pregrado). Escuela universitaria de educación de Palencia, Palencia, España.

Fernández, M. (2014). Estimular el placer de leer: Propuesta de animación lectora para alumnos de sexto de primaria (tesis de pregrado). Universidad Internacional de la Rioja, La Rioja, España.

Marqués, P. (1996), Los medios didácticos y los recursos educativos. (tesis de pregrado). Universidad Autónoma de Chile, Santiago de Chile, Chile.

Quintanal, J. (2005). La animación lectora en el aula. Madrid, España: Editorial CCS.

Quintanal, J. (2000). Animación a la lectura, España: Editorial CCS.

Robledo, B. H. (2010). El arte de la mediación: espacios y estrategias para la promoción de la lectura. Bogotá, Colombia: Editorial Norma.

Solé, I. (septiembre de 1995). El placer de leer. Revista latinoamericana de lectura. (3), 2-8.

Tapia, J. (1997). Motivar para el aprendizaje. Teoría y estrategias. España: Editorial EDEBÉ.

Valdivia, P. (2009). Guía de actividades de animación. Recuperado de https:// hurukuta.blogspot.com.co/ 